\title{
Economic Valuation of Forest Conserved by Local Community for Carbon Sequestration: The Case of Humbo Community Assisted Natural Regeneration Afforestation/Reforestation (A/R) Carbon Sequestration Project; SNNPRS, Ethiopia
}

\author{
Elmi Nure Negewo, Zeleke Ewnetu, Yemiru Tesfaye \\ Hawassa University, Wondo Genet College of Forestry and Natural Resources, Hawassa, Ethiopia \\ Email:elminegewo@gmail.com,zeleke ewnetu@yahoo.com, tyemiru@yahoo.com
}

Received 13 February 2016; accepted 24 June 2016; published 27 June 2016

Copyright (C) 2016 by authors and Scientific Research Publishing Inc.

This work is licensed under the Creative Commons Attribution International License (CC BY).

http://creativecommons.org/licenses/by/4.0/

c) (i) Open Access

\section{Abstract}

The study was carried out to determine the economic value of forest conserved by local community for carbon sequestration in the Humbo District, Ethiopia. The contingent valuation method (CVM) using the double bounded bivariate probit econometric method was employed to estimate WTP for sustainable forest management. Household survey was randomly conducted in 218 respondents purposively selected from three forest development cooperatives. The bivariate probit model was run to estimate mean WTP and to identify the determinant factors for farmers' WTP for forest conservation. Thus, the mean WTP with covariates was estimated to be 104.38 Ethiopian Birr (ETB) and 55.73 ETB $^{1}$ per year for the initial bid and for the follow-up bid amount, respectively. The result also indicated that respondents' level of education, marital status, years of membership in the cooperatives, second bid amount, distance of residence from forest of interest, and net family income were significantly related to WTP for forest conservation. The study showed that even the poor households were willing to pay the average values in terms of cash contribution to maintain the forest management responsibility following the withdrawal of the NGO. In conclusion, whereas CVM can be applied to determine WTP for forest conservation, local people recognize and give value to the environmental services of the forest and are willing to maintain those

${ }^{1}$ Currency Exchange rate of National Bank of Ethiopia as of 24/06/2012; 1USD = 18.0532 Ethiopian birr (ETB).

How to cite this paper: Negewo, E.N., Ewnetu, Z. and Tesfaye, Y. (2016) Economic Valuation of Forest Conserved by Local Community for Carbon Sequestration: The Case of Humbo Community Assisted Natural Regeneration Afforestation/Reforestation (A/R) Carbon Sequestration Project; SNNPRS, Ethiopia. Low Carbon Economy, 7, 88-105. 
benefits. The study also indicates the potential for sustainable forest management through community-based approach.

\title{
Keywords
}

\author{
Contingent Valuation Method, Sustainable Forest Management, Carbon Sequestration
}

\section{Introduction}

The world forest covers about 4 billion hectares of land. The forest cover of Africa was close to 674 million hectare out of which 73 million hectare was the share of East Africa. During the same period, Ethiopia also had a forest cover of 12 million hectare which almost covered $11 \%$ of the land [1].

Forest resources are the most productive ecosystems providing a wide range of important ecological functions, life supporting and other services. Forestry can play significant role in boosting economic development of agrarian countries like Ethiopia. However, the contribution of forestry sector to the country's GDP in promoting the whole economy as compared to agriculture sector has been very low (5.5\%). The reason was attributed to policy failure and market imperfection resulting from lack of measurement and valuation of the non-marketable goods and services obtained from forest resources [2].

As in the rest parts of developing countries, the response of Ethiopia to the challenge of climate change has considerably been increased over the years. Ethiopia is a signatory to Kyoto protocol in 2005 and parties to the convention. One of the remarkable roles played by the country was the launching of Humbo Community Assisted Natural Regeneration Aforestation/Reforestation (A/R) implemented under Clean Development Mechanism (CDM) both to ensure sustainable development and emission reduction. Humbo project is the second largest registered carbon project in the world next to China's CDM project [3].

The project has a potential to sequester a total of 880,295 tons of carbon dioxide equivalent $\left(\mathrm{CO}_{2}\right.$ equivalent tons) throughout its crediting period (30 years). But, World Bank has signed purchase agreement only for $165,000 \mathrm{t} \mathrm{CO}_{2 \mathrm{e}}$ sequestered over the first ten years period, from which has a value of $\$ 726,000$.

The project has been implemented by World Vision Ethiopia with the financial and technical support from World Vision Australia in collaboration with the government of Ethiopia and local community. World Bank has also been providing the required technical support and community capacity building fund. But, World Vision Ethiopia has a plan to handover the project to Forest development cooperatives at the end of year 2014. Thus, the community is expected to fully handle the overall resource management under sustainable basis. Although the forest production (Forest management activities) and transaction costs will be minimum in the years to come but, the community is expected to cover any costs incurred to run the business afterwards. Hence, this research paper gave emphasis to assess community's willingness to pay (WTP) to maintain forest management for the benefit of future carbon sequestration and other environmental co-benefits in the absence of World Vision Ethiopia throughout the project life [4].

\section{Study Area}

The study was conducted in Humbo Woreda, Wolaita Zone, Southern Nations Nationalities and Peoples Regional State (SNNPRS), South Western of Ethiopia. Humbo is one of the twelve rural districts in Wolaita Zone. The total population of the district was 132,780. The district has 36 local level Administrative (Kebeles) out of which 35 is rural and 1 urban Administration covering a total land area of 97,363 ha [5]. Forest development cooperatives encompass seven rural Kebeles namely Abela Gefeta, Abela Longena, Abela Shoya, Bola Wanche, Bosa Wanche, Hobicha Bada and Hobicha Bongota. The Humbo (Tebela) town, capital of the district geographically located in approximate coordinate of $6^{\circ} 46^{\prime} 48.47$ to $6^{\circ} 41^{\prime} 04.28 \mathrm{~N}$ latitude and $37^{\circ} 48^{\prime} 35.44$ to $37^{\circ} 55^{\prime} 14.51 \mathrm{E}$ longitude. The study site covers a total of 2728 ha which is dominated by naturally regenerated vegetation. The project is the first in its kind in Africa and also registered by United Nations Framework Convention on Climate Change (UNFCCC) as of December 2009. The forest ecosystem is fully under management of legally organized seven forest users group granted exclusive user right by respective local government. The forest users groups are living at the periphery of the project site [6] (Figure 1). 

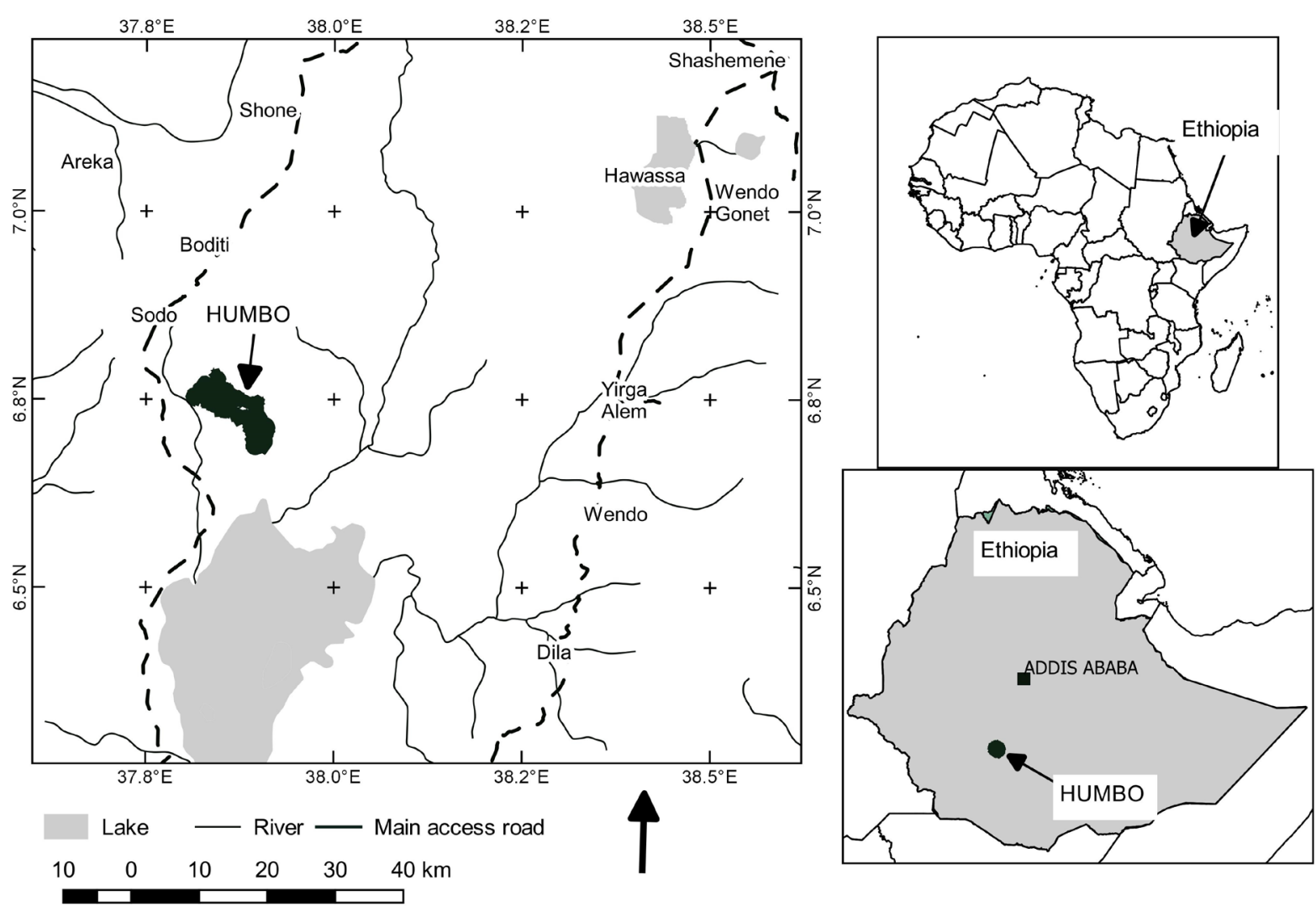

Figure 1. Map of the studay area.

\section{Data and Methodology}

The sampling frame for survey included those households that are legally organized as forest development cooperatives to manage the forest of interest. A two stage sampling procedures was employed to select the sample households in the study area. In the first stage, three representative Cooperatives out of seven were purposively selected on the basis of their accessibility and representativeness (Abela Longena, Hobicha Bada and Abela Shoya. In the second stage, Proportional sampling technique was applied to draw samples from the population. Thus, $10 \%$ of the households from each cooperative were included in the sample i.e. 85,84 and 49 households were selected respectively from each Cooperatives using systematic random sampling technique irrespective of their sex, social and economic status. This would thus give a total of 218 sample households for the survey.

The survey was conducted to generate empirical data through estimating individual's stated WTP to manage the forest of interest. Household survey was conducted to gather qualitative and quantitative data from randomly selected individual respondents. A double-bounded elicitation format was employed.

The payment situation was well described in the questionnaire and the respondents were presented with the WTP question that included one of five different starting amounts (five bid levels) in Birr (10, 20, 30, 40 and 50) which was randomly assigned. If the respondents answer the first question affirmatively, then the amount was increased (doubled) otherwise, it was decreased (halved). The payment vehicle used was cash payment on per year payment basis. Key informants were also asked to assess the prospect of community in view of forest management.

Model specification: Contingent valuation method was applied to elicit the people's willingness-to-pay for the environmental change (improved forest ecosystem through carbon sequestration). This method is particularly applicable in a situation where market information about people's preference is absent. Thus, this study adopts the model developed by Cameron and Quiggin and aims at identifying the true WTP of the forest development cooperatives and assessing determining factors using single and bivariate probit model. Accordingly single bound probit model takes the following form [7]. 


$$
\begin{gathered}
Y_{i}=X_{i} \beta+\varepsilon_{i} \\
I=1 \text { if } y_{i} \geq t_{i} \\
I=0 \text { if } y_{i}<t_{i}
\end{gathered}
$$

where

$Y_{i}=i^{\text {th }}$ respondent's true unobserved point valuation for the environmental resource in question,

$\beta=$ a coefficient for $X$,

$t_{i}=$ the offered threshold, assigned arbitrarily to the $i^{\text {th }}$ respondent,

$I=$ discrete response of a respondent for the WTP question $(1=$ yes, $0=$ no),

$\varepsilon_{i}=$ unobservable random component distributed $\mathrm{N}(0, \sigma)$,

$X_{i}=$ observable attributes of the respondent.

Bivariate Probit Model: Bivariate normal probability density functions are the most familiar bivariate distributions employed commonly by statisticians; they allow for a non-zero correlation, whereas the standard logistic distribution (logit model) does not [8]. Hence, the bivariate probit model was employed in this study to estimate the mean WTP and determinant factors that affect WTP from the double bounded dichotomous choice.

The model takes the following form [9].

The $j^{\text {th }}$ contribution to the Likelihood function is given as

$$
\begin{aligned}
L_{j}(\mu / t)= & \operatorname{Pr}\left(\mu_{1}+\varepsilon_{1 j}>t_{1}, \mu_{2}+\varepsilon_{2 j}<t_{2}\right)^{Y N} * \operatorname{Pr}\left(\mu_{1}+\varepsilon_{1 j}>t_{1}, \mu_{2}+\varepsilon_{2 j}>t_{2}\right)^{Y Y} \\
& * \operatorname{Pr}\left(\mu_{1}+\varepsilon_{1 j}<t_{1}, \mu_{2}+\varepsilon_{2 j}<t_{2}\right)^{N N} * \operatorname{Pr}\left(\mu_{1}+\varepsilon_{1 j}<t_{1}, \mu_{2}+\varepsilon_{2 j}>t_{2}\right)^{N Y}
\end{aligned}
$$

This formulation is referred to as the bivariate discrete choice model, where

$\mu=$ mean value for willingness to pay,

$Y Y=1$ for a yes-yes answer, 0 otherwise, $N Y=1$ for a no-yes answer, 0 otherwise, etc.

And the $j^{\text {th }}$ contribution to the bivariate probit Likelihood function becomes

$$
L_{j}(\mu / t)=\Phi_{\varepsilon 1 \varepsilon 2}\left(d_{1 j}\left(\left(t_{1}-\mu_{1}\right) / \sigma_{1}\right), d_{2 j}\left(\left(t_{2}-\mu_{2}\right) / \sigma_{2}\right), d_{1 j} d_{2 j} \rho\right)
$$

where: $\Phi_{\varepsilon 1 \varepsilon 2}=$ Standardized bivariate normal distribution function with zero means,

$y_{1 j}=1$ if the response to the first question is yes, and 0 otherwise,

$y_{2 j}=1$ if the response to the second question is yes, 0 otherwise,

$d_{1 j}=2 y_{1 j}-1$, and $d_{2 j}=2 y_{2 j}-1$,

$\rho=$ correlation coefficient,

$\sigma=$ standard deviation of the errors.

The general model can be readily estimated using standard packaged bivariate probit algorithms using STATA (version 10) software.

Estimation Techniques: A dichotomous choice contingent valuation method with follow-up questions was used to elicit the mean WTP of the respondents to observe the changes in the forest of interest. The dependent variable in the model is a dummy variable, which assumes either 0 or 1 . The use of dichotomous choice questions with follow-up bids implies that the response for the second question is endogenous to that of the first. This means that, the model cannot be estimated using the ordinary probit/logit model. Thus, bivariate probit model, which simultaneously estimate the two equations, was employed in order to minimize the misrepresentation that might be happen due to the endogenous characteristics of the second response.

\section{Results and Discussion}

\subsection{Results}

\section{Households Social, Economic, Environmental and Demographic Characteristics}

The respondents' age ranges from 17 to 90 and a significant proportion of them (81.7\%) are within the active labor force (Table 1). The average age for the household head is 40.63 years. The sampled households are characterized by large family size. As indicated below (Table 1) about $73 \%$ of the households have 4 to 9 members 
Table 1. Descriptive stastistics of variables used in the analysis.

\begin{tabular}{ccccc}
\hline Variable & Mean & Std. Dev. & Min & Max \\
\hline Sex of respondent (SexR) male $=0$ & 0.1972 & 0.3988 & 0 & 1 \\
Age of respondent (AgeR) & 40.577 & 13.294 & 17 & 90 \\
Family size of respondent (FamSR) & 6.4311 & 2.6181 & 1 & 11 \\
Education level of respond. = (EduR), attend form.edu =1 & 0.4678 & 0.5001 & 0 & 1 \\
Marital status of respondent (MarR) married =1 & 0.8853 & 0.3193 & 0 & 1 \\
Years of membership (YearM) & 4.0412 & 1.0789 & 2 & 6 \\
Distance from forest site (DistR) & 0.2889 & 0.4543 & 0 & 1 \\
Environmental know of respondent (EnAR) & 0.7981 & 0.4022 & 0 & 1 \\
First bid amount (Fbid) & 29.770 & 14.189 & 10 & 50 \\
Second bid amount (Sbid) & 36.926 & 14.770 & 5 & 60 \\
Net income (Ntincome) & 4201.5 & 1616.3 & 2000 & 8720 \\
Maximum willingness to pay (MWTP) & 48.096 & 27.988 & 0 & 150 \\
\hline
\end{tabular}

Source: Survey result, 2012.

which on average leads to high dependency ratio of 5.07. The average family size of the sampled households is 6.43 with a range of 1 to 11 family members. About $88 \%$ of the respondents were married, while the remaining $12 \%$ were unmarried and these includes widows and divorced heads of household. As far as the education level of the respondents is concerned, $53 \%$ of them are illiterate. This indicates that most of the respondents had no access to formal education.

Distance is dummy variable 1 for residents living proximate to forest of interest 0 other wise and referring to the respondent's location from forest of interest. Thus, the survey result indicated that $71 \%$ of the respondents residing proximate to forest of interest. Number of years of membership is also continuous variable and refers to number of years that the respondents have been staying in the cooperatives as a member. The time respondents became cooperatives member was vary from 2 to 6 years having a mean of 4.04 years on average. Accordingly, the study indicated that all of the respondents were member for two and more years in the forest development cooperatives (Table 1 ).

Income: is continuous variable indicating the net amount of income earned by respondents from various sources in birr value per annum. Thus, the study result showed that the community entertained different sources of income although limited in number. The major sources of income involve farming, off-farm and natural resources. In order to get detailed and valid information gross income of various sources calculated for the past twelve months. Then after, net income computed by deducting different costs incurred from gross income. Accordingly, the minimum net annual family income found to be 2000 while the maximum was 8720 ETB. Based on this approach, mean value of net annual income from various activities was estimated to be 4201 ETB per household (Table 1). Taking the mean family size as 6.43, the per capita income becomes $113^{2}$ ETB per month, which is less as compared to the forecasted 156.69 ETB national average per capita income [10].

Environmental Knowledge: this variable has a positive relationship with respondents WTP to manage the forest. The more the environmental knowledge means the better the respondents know environmental benefits and this could be expressed through contribution. Thus, $79.8 \%$ of the respondents have environmental knowledge of their locality ${ }^{3}$ (Table 1).

Bids Amount: Refers to the variable with different threshold values offered randomly to be responded for accordingly. Thus, it was assumed that the higher the threshold value proposed, the less willing the respondent to pay for the resources in question. So, it is expected to have negative sign. Five threshold values offered as starting bid i.e.10, 20, 30, 40 and 50 ETB). Thus, the offered minimum first bid amount is 10 ETB while the maximum is 50 ETB with the average starting bid amount is 29.77 ETB. The second bid amount is $5,10,20,30$, 40, 50 and 60 ETB with mean value of 36.92 ETB (Table 1).

\footnotetext{
${ }^{2}$ The per capita income is estimated by dividing the total income to average family size and again divided to 12 months [(8720/6.43)]/12 months.

${ }^{3}$ Assessed by asking respondents to remember the environmental situation of where they have been living in consideration of absence/presence of forest management. Further they were asked to rate their knowledge of environmental problems/benefits prevailing in respective area.
} 


\section{Environmental Situation of the Study Area}

Before forestry project there were major environmental problems. The major environmental problems includes; deforestation, soil erosion and climatic variability. Accordingly, in relation to the depletion of forest resources (deforestation) 27\% respondents expressed that they had medium knowledge while $71 \%$ had high knowledge of deforestation and the remaining $2 \%$ had no knowledge. About $61 \%$ of the respondents had high knowledge of soil erosion problem. About $37 \%$ of the respondents had medium knowledge while only $2 \%$ of the respondents had no knowledge of soil erosion. From climatic change and variability problem point of view, only $2 \%$ of respondents had no knowledge, $46 \%$ medium while the remaining $52 \%$ had high knowledge (Table 2).

As far as environmental problem of the study area is concerned, various factors have different level of severity status to impose at particular locality. In this respect, $56 \%$ of the respondents indicated that deforestation was a big challenge followed by soil erosion $42 \%$. As a result of deforestation; environmental problems like climate variability (29\%), depletion of water sources (29\%) and loss of biodiversity (45\%) ranked third, fourth and fifth order of severity level respectively (Table 3).

Following the commencement of the Project, various environmental benefits have been appearing due to project conservation practices (Table 4). Thus, benefits were also assessed to see the status of respondents' environmental knowledge. Respondents expressed a positive impact on their livelihoods since rehabilitation of the degraded natural forest.

Table 2. Environmental problems preailed in the studay area.

\begin{tabular}{|c|c|c|c|c|}
\hline \multirow{2}{*}{ Environmental problems } & \multicolumn{3}{|c|}{ Status of understanding the problem (\%) } & \multirow[b]{2}{*}{ Tota } \\
\hline & No & Medium & High & \\
\hline Deforestation & 2 & 27 & 71 & 100 \\
\hline Soil erosion & 2 & 37 & 61 & 100 \\
\hline Climate variability & 2 & 46 & 52 & 100 \\
\hline
\end{tabular}

Source: Survey result, 2012.

Table 3. Respondents' ranking order of environmental problem.

\begin{tabular}{cccccc}
\hline \multirow{2}{*}{ Environmental problem } & \multicolumn{5}{c}{ Order of environmental problem (level of severity) } \\
\cline { 2 - 6 } & $1^{\text {st }}(\%)$ & $2^{\text {nd }}(\%)$ & $3^{\text {rd }}(\%)$ & $4^{\text {th }}(\%)$ & $5^{\text {th }}(\%)$ \\
\hline Deforestation & $\mathbf{5 6}$ & 18 & 9 & 14 & 22 \\
Loss of biodiversity & 2 & 14 & 17 & 22 & $\mathbf{4 5}$ \\
Climate change & 12 & 18 & $\mathbf{2 9}$ & 20 & 3 \\
Soil erosion & 17 & $\mathbf{4 2}$ & 18 & 15 & 7 \\
Depletion of water sources & 13 & 8 & 27 & 100 & 23 \\
Total & 100 & 100 & 100 & 100 \\
\hline
\end{tabular}

Source: Survey result, 2012.

Table 4. Ranking of environmental and economic benefits.

\begin{tabular}{|c|c|c|c|c|c|c|c|}
\hline \multirow{2}{*}{ Environmental benefits } & \multicolumn{7}{|c|}{ Rank (\% of respondents) } \\
\hline & $1^{\text {st }}$ & $2^{\text {nd }}$ & $3^{\text {rd }}$ & $4^{\text {th }}$ & $5^{\text {th }}$ & $6^{\text {th }}$ & $7^{\text {th }}$ \\
\hline Improved water sources & 10 & 17 & 17 & 19 & 13 & 10 & 13 \\
\hline Improved microclimate & 43 & 23 & 20 & 8 & 4 & 2 & 1 \\
\hline Reduced soil erosion & 22 & 28 & 22 & 10 & 14 & 3 & 2 \\
\hline Improved biodiversity & 1 & 5 & 12 & 12 & 19 & 24 & 28 \\
\hline Created job opportunity & 5 & 2 & 6 & 14 & 21 & 29 & 22 \\
\hline Improved fuel wood sources & 11 & 10 & 4 & 15 & 15 & 18 & 26 \\
\hline Improved sources of grass & 8 & 15 & 19 & 22 & 14 & 14 & 8 \\
\hline Total & 100 & 100 & 100 & 100 & 100 & 100 & 100 \\
\hline
\end{tabular}

Sources: Survey result, 2012. 
The study result indicated that $100 \%$ of the respondents said "yes" to the positive impacts of rehabilitation effort. Hence, the most frequently mentioned environmental benefit was the improved microclimate $(43 \%)$ of the respective area and followed by reduced soil erosion (28\%). The third important factor was improved availability of grass (19\%) to feed their livestock, which also positively impacted the livelihood of respective community through sale of grass and increased milk production. Moreover, increased water availability (19\%), creation of job opportunity (21\%) and improved biodiversity (24\%) ranked fourth, fifth and sixth respectively while, fuel wood sources ranked the last (Table 4).

The community banned from fuel wood collection and cutting of live trees for other purposes due to leakage problem. But, during thinning operation communities have a change fetch twigs and branches for household consumption. Moreover, they also used fuel wood from their own home yard. On top of this, the project also provide tree seedlings to community for free as a buffer plantation for further use.

\section{Descriptive Statistics for Double Bounded Dichotomous Choice Questions}

The average amount of the $1^{\text {st }}$ bid is 29.77 ETB per year but the value increased to 36.93 ETB for the $2^{\text {nd }}$ bid amount (Table 5). By the same token, the "yes" response for the $1^{\text {st }}$ bid is $91 \%$ and $83 \%$ for the second bid respectively. However, the distribution of "yes" and "No" for the $1^{\text {st }}$ and $2^{\text {nd }}$ bids across the different initial bids indicated, as the initial bid gets higher the frequency of "No" response increases. Hence, even though high total proportion for the $1^{\text {st }}$ response entertains the higher follow up bids, the average for the $2^{\text {nd }}$ bids was higher than the initial bid average. From the joint frequencies of discrete responses it was possible to draw that, about $73 \%$ responded "Yes" for both the $1^{\text {st }}$ and $2^{\text {nd }}$ bids, about $17 \%$ responded "Yes-No", and about $2 \%$ responded "No-No" while, $8 \%$ responded "No-Yes" (Table 6). Hence, this distribution indicated that $73 \%$ of the respondents who accepted the $1^{\text {st }}$ bid gave similar response for the follow up question and $2 \%$ of those who rejected the $1^{\text {st }}$ bid again rejected the $2^{\text {nd }}$ bid.

About $91 \%$ of the 44 respondents of the $10 \mathrm{ETB}$ initial bid accepted both $1^{\text {st }}$ and $2^{\text {nd }}$ bids i.e. 10 and 20 ETB and about $76.6 \%$ of the 43 respondents of the 50 ETB with initial bid accepted both $1^{\text {st }}$ and $2^{\text {nd }}$ bids $(50$ and 60 ETB). This indicates that as the $1^{\text {st }}$ bid get increased the number of voters decreased. Generally, it is possible to note that as the initial bid gets higher the share of "Yes" response for the initial bid decreases. The result of Figure 2 also shed more light on this indicating that, as the bids increased the "Yes" response for both bids decreased at an increasing rate.

Table 5. Responses for double bounded dichotomous questions.

\begin{tabular}{|c|c|c|c|c|c|}
\hline Acronym & Description & Mean & St. D & Min & Max \\
\hline $\mathrm{t}_{1}$ & Exogenous threshold ${ }^{4}\left(t_{1}\right)$ for the first question & 29.77 & 14.19 & 10 & 50 \\
\hline $\mathrm{t}_{2}$ & Endogenous threshold $\left(\mathrm{t}_{2}\right)$ for second question & 36.93 & 14.77 & 5 & 60 \\
\hline $\mathrm{I}_{1}$ & Discrete response of the $1^{\text {st }}$ question $(1=$ yes, $0=$ no) & 0.91 & 0.283 & 0 & 1 \\
\hline $\mathrm{I}_{2}$ & Discrete response for $2^{\text {nd }}$ question $(1=$ yes, $0=$ no $)$ & 0.83 & 0.380 & 0 & 1 \\
\hline
\end{tabular}

Source: Survey result, 2012.

Table 6. Frequency distribution of double bound discrete response.

\begin{tabular}{ccccc} 
Discrete response & Freq. & Mean & St. Dev & 0.440 \\
Yes-Yes (YY) response for both questions & 161 & 0.73 & 0 \\
Yes-No (YN) response for both questions & 36 & 0.17 & 0.372 \\
No-Yes (NY) response for both questions & 17 & 0.08 & 0.269 \\
No-No (NN) response for both questions & 4 & 0.02 & 0.135 \\
Total & 218 & 1 & 0 \\
\hline
\end{tabular}

Source: Survey result, 2012.

${ }^{4}$ Exogenous threshold refers to the first bid and the response to this bid is not affected by endogenous threshold (second bid) but, the second bid response will be affected by first bid response. 


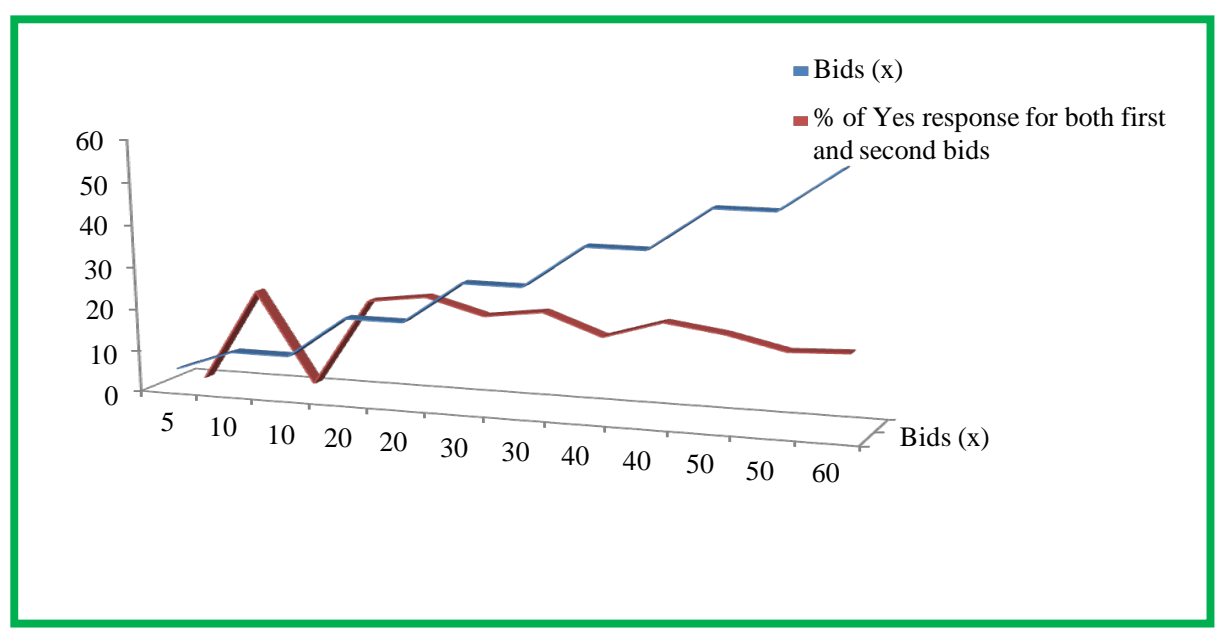

Figure 2. Percentage of yea response for both first and second bid choice values.

Multicollinearity: multicollinearity is referring to the existence of a "perfect" or "exact", linear relationship among some or all explanatory variables of a regression model [11]. Thus, it is important to check for multicollinearity problem before running the model against the hypothesized explanatory variables. The existences of multicollinearity will hinder to derive estimators of parameter coefficient and thus make statistical inference difficult. As collinearity increases, the variances of the estimators increase and in the limit it can become infinite. This means that, as the variance of an estimator increases toward 1 , the covariance of the two estimators also increases in absolute value. Thus, the speed with which variances and covariances increase will be computed using variance-inflating factor (VIF). The VIF shows how the variance of an estimator is inflated by the presence of multicollinearity. As the variance of an estimator approaches 1, the VIF approaches infinity. That is, as the extent of collinearity increases, the variance of an estimator increases, and in the limit it can become infinite.

$$
\text { The formula of VIF can be expressed as: } \operatorname{VIF}\left(X_{I}\right)=\frac{1}{1-R_{i}^{2}}
$$

where, $R_{i}^{2}$ is the coefficient of multiple correlations in which the variable $X_{i}$ is regressed on the other hypothesized explanatory variable. Thus there is a consensus that, when the value of VIF of a given variable exceeds 10 (this happen if $\mathrm{R}^{2}$ exceeds 0.95 ), that variables are said to be highly collinear. Therefore, in this study the computed variance inflation factor (VIF) result indicated that there was no multicollinearity problem among hypothesized explanatory variables (Table 7).

Finally, after passing through aforementioned serious of steps, the results of explanatory variables were presented in table below (Table 8 and Table 9).

The result indicated that, all explanatory variables are not significant while the overall model is significant at $5 \%$ level. As it was expected, although distance of the respondents and the offered first bid insignificant but negatively will affect their WTP for the resources in questions. Moreover, in contrast to the expectation; marital status, year of being membership and environmental knowledge are found insignificant and also negatively affected their WTP to manage the forest of interest (Table 8). Thus, as per the recommendation by [7] it seems better to run the bivariate probit model to get individuals innate behavior, because the result of the doublebounded dichotomous choice is more efficient statistically than single-bounded probit model.

Mean Willingness to Pay (Mean WTP) for Carbon Forestry Project Management and Estimation of Explanatory Variables from Double Bounded Dichotomous Choice Question

The mean willingness to pay $(\mu)$ was calculated using the formula [9]

$$
\mu=-\alpha / \beta
$$

where: $\alpha=$ a coefficient for the constant term,

$\beta=$ a coefficient for the amount of the bid that the family was asked to pay.

From the summarized responses for the first and the second bids, a total of 436 usable responses were obtained. 
Table 7. Test of colliniarity statistics for explanatory variables.

\begin{tabular}{|c|c|c|c|c|c|c|c|c|c|c|}
\hline \multirow{2}{*}{ Variables } & \multirow{2}{*}{$\begin{array}{c}\text { Collinearity } \\
\text { statistics } \\
\text { VIF } \\
\end{array}$} & \multicolumn{9}{|c|}{ Coefficient correlations } \\
\hline & & Distance & $\begin{array}{l}\text { Family } \\
\text { size }\end{array}$ & $\begin{array}{c}\text { Environ. } \\
\text { know }\end{array}$ & Education & Sex & Income & $\begin{array}{l}\text { Year of } \\
\text { mem. }\end{array}$ & Age & $\begin{array}{c}\text { Marital } \\
\text { status }\end{array}$ \\
\hline Distance & 1.116 & 1 & & & & & & & & \\
\hline Family size & 1.252 & -0.012 & 1 & & & & & & & \\
\hline $\begin{array}{c}\text { Environ. } \\
\text { know }\end{array}$ & 1.026 & -0.001 & -0.072 & 1 & & & & & & \\
\hline Education & 1.145 & 0.015 & -0.070 & -0.024 & 1 & & & & & \\
\hline Sex & 1.169 & -0.090 & -0.119 & 0.053 & 0.137 & 1 & & & & \\
\hline Income & 1.026 & -0.186 & 0.059 & 0.001 & -0.052 & -0.036 & 1 & & & \\
\hline $\begin{array}{l}\text { Year of } \\
\text { mem. }\end{array}$ & 1.038 & 0.200 & -0.134 & 0.127 & -0.030 & -0.021 & -0.009 & 1 & & \\
\hline Age & 1.247 & -0.115 & -0.298 & 0.043 & 0.305 & 0.018 & 0.017 & 0.034 & 1 & \\
\hline $\begin{array}{l}\text { Marital } \\
\text { status }\end{array}$ & 1.276 & 0.026 & -0.283 & 0.070 & -0.060 & 0.330 & 0.079 & 0.068 & -0.074 & 1 \\
\hline
\end{tabular}

Source: Survey result, 2012.

Table 8. Probit estimate for the single bounded dichotomous choice model.

\begin{tabular}{|c|c|c|c|}
\hline Variables & Probit coefficients & $\mathrm{P}>/ \mathrm{Z} /$ & SD error \\
\hline Sex of respondent (SexR) & 0.0485278 & 0.885 & 0.334660 \\
\hline Age of respondent (AgeR) & 0.0116001 & 0.325 & 0.011779 \\
\hline Family size of resp. (FamSR) & 0.0035174 & 0.941 & 0.047666 \\
\hline Education level of resp. (EduR) & 0.0798405 & 0.741 & 0.241491 \\
\hline Marital status of resp. (MarR) & -0.509332 & 0.311 & 0.502486 \\
\hline Years of membership (YearM) & -0.0209681 & 0.845 & 0.107086 \\
\hline Distance from forest site (DistR) & -0.0112761 & 0.966 & 0.261984 \\
\hline Environmental know. (EnAR) & -0.174373 & 0.589 & 0.322713 \\
\hline First bid amount (Fbid) & -0.0045734 & 0.617 & 0.009149 \\
\hline Net income (Ntincome) & 0.0000344 & 0.585 & 0.000063 \\
\hline \multirow[t]{6}{*}{ _Constant } & 1.525866 & 0.118 & 0.975572 \\
\hline & servation & & 218 \\
\hline & (10) & & 3.89 \\
\hline & & & 0.9523 \\
\hline & & & $0.0263 * *$ \\
\hline & kelihood & & -62.81106 \\
\hline
\end{tabular}

Source: Survey result, 2012; Note: ${ }^{* * *}, * *$, * indicates significance level at $1 \%, 5 \%$ and $10 \%$.

Double-bounded contingent valuation model is used to estimate the mean willingness-to-pay and its determinants. There are two options of independent models which can be used to estimate mean WTP. The models are bivariate model with no covariates i.e. WTP checked against the offered amount and bivariate model with covariates i.e. WTP against age, gender, education, family size, distance from forest of interest, marital status, years of being cooperatives membership, environmental awareness, offered amount and family net income. Thus, before deciding on which model to apply, it seems important to compare their results which would help to capture the true behavior of people that expressed through their preferences. Thus, the result from the second model was preferred for it uses covariates to run the model (Table 9). Thus, the result revealed that, the mean WTP for managing the forest of interest after taking over from World Vision Ethiopia for the two simultaneously run equations is Birr 104.38 and Birr 55.73 per household per year, respectively. As indicated by the Pro $>$ chi $^{2}=$ 0.0001 , the model is significant at $1 \%$ significance level (Table 9). 
Table 9. Results of bivariate probit parameter estimates from the double bound with Covariates.

\begin{tabular}{|c|c|c|c|c|c|c|}
\hline \multirow{2}{*}{ Variables } & \multicolumn{2}{|c|}{ Probit coefficient } & \multicolumn{2}{|c|}{$\mathrm{P}>/ \mathrm{Z} /$} & \multicolumn{2}{|c|}{ SD Error } \\
\hline & Model-I & Model-II & M-I & Model-II & Model-I & Model-II \\
\hline Sex of respondent (SexR) & 0.0861159 & 0.1438551 & 0.794 & 0.607 & 0.330000 & 0.2796774 \\
\hline Age of respondent (AgeR) & 0.013639 & -0.0031993 & 0.244 & 0.741 & 0.011701 & 0.0096613 \\
\hline Family size of respondent & -0.0002078 & 0.0265806 & 0.997 & 0.564 & 0.047457 & 0.0460547 \\
\hline Education level (EduR) & 0.1081521 & 0.6739087 & 0.653 & $0.005^{* * *}$ & 0.240503 & 0.2385764 \\
\hline Marital status (MarsR) & -0.4990871 & 0.9732873 & 0.311 & $0.005^{* * *}$ & 0.492557 & 0.3492515 \\
\hline Years of membership & -0.0326813 & -0.274606 & 0.768 & $0.002 * * *$ & 0.110678 & 0.0897633 \\
\hline Distance from forest site & 0.0272502 & -1.201628 & 0.917 & $0.000^{* * *}$ & 0.261239 & 0.2461782 \\
\hline Environmental Know & -0.2023155 & 0.3056021 & 0.524 & 0.283 & 0.317381 & 0.2845043 \\
\hline First bid amount (Fbid) & -0.0143836 & NA & 0.635 & NA & 0.009223 & NA \\
\hline Second bid amount (Sbid) & NA & -0.022867 & NA & $0.005^{* * *}$ & NA & 0.0081606 \\
\hline Net income (Ntincome) & 0.000033 & 0.000176 & 0.604 & $0.014^{* *}$ & 0.000063 & 0.0000716 \\
\hline _Constant & 1.501364 & 1.274501 & 0.11 & 0.115 & 0.938756 & 0.8096034 \\
\hline Number of observation & \multicolumn{6}{|c|}{218} \\
\hline Wald Chi' ${ }^{2}(20)$ & \multicolumn{6}{|c|}{51.20} \\
\hline Rho (p-value) & \multicolumn{6}{|c|}{0.424529} \\
\hline Prob $>\mathrm{Chi}^{2}$ & \multicolumn{6}{|c|}{$0.0001^{* * *}$} \\
\hline Log pseudo likelihood & \multicolumn{6}{|c|}{-135.30805} \\
\hline $\operatorname{Chi}^{2}(1)$ & \multicolumn{6}{|c|}{3.69662} \\
\hline
\end{tabular}

Source: Survey result, 2012; Note: ${ }^{* * *}, * *$ and $*$ indicate significance level at $1 \%, 5 \%$ and $10 \%$ respectively.

The quantity $\mathrm{Chi}^{2}\left(\chi^{2}\right)$ illustrated (Table 9 ) a full test of significance. Thus, the null hypothesis was that all explanatory variables including the constant term assumed to be zero. Under the null hypothesis, the tabled Chi-square for 9 degrees of freedom at 99\% confidence level equals 21.66, so that the hypothesis is rejected.

Family size, education level, marital status, years of membership, distance of residence from forest site, environmental knowledge and the net family income did not significantly affect the WTP. In contrary Applying equation (5) above, the coefficients of constant term divided to the coefficient of offered amount to estimate the mean willingness to pay for forest management. Accordingly, the double bounded bivariate probit estimate (with covariates) of the mean willingness to pay ranged from 104.38 ETB to 55.73 ETB for the initial bid (Fbid) and for the follow up second bid amount (Sbid) respectively. Generally, this figure was much higher than the mean willingness to pay amount from the open-ended question (Maximum WTP) which was 48.0963 ETB. Also the mean WTP of single bounded probit estimate was highly exaggerated than that of the double bounded estimate. Mean WTP will be overestimated if a cumulative density function estimated from dichotomous choice data has an unrealistically fat right-hand tail. If a cumulative density function estimated from dichotomous choice data has an unrealistically fat right-hand tail, mean WTP will be overestimated [12].

\section{Determinant Factors Affecting Respondents WTP}

Furthermore, respondents' exposed to various socio-economic and demographic situations which will influence their mean willingness-to-pay. Following the results of bivariate probit analyses, the variables that were expected to influence the respondent's willingness to pay for managing forest resources after taking over from World Vision Ethiopia (Table 9).

To see the marginal effect of each of ten (10) independent variables on individual's WTP for the forest of interest the bivariate probit model was run (Table 10). Thus, the marginal effects of each of explanatory variables were discussed as hereunder.

Membership of Forest Development Cooperatives (YearM): Years of being cooperatives Membership of the respondents is negative and significant at $1 \%$. This indicated that respondents have a claim for a benefit share from the sale of carbon credit at individual basis. Due to this grievance they negatively react to pay for the respective resource management. As evidence to this, keeping other factors constant one year additional as being 
Table 10. Marginal effect of explanatory variables on WTP.

\begin{tabular}{cccc}
\hline Variable & Marginal effect & Variable & Marginal effect \\
\hline Sex of respondent (SexR) & 0.0315871 & Years of Membership & -0.0481639 \\
Age of respondent (AgeR) & 0.001007 & Distance from forest site & -0.2624886 \\
Family size of respondent & 0.004285 & Environmental Know & 0.0371538 \\
Education level (EduR) & 0.1195714 & Net Income & 0.0000322 \\
Marital status (MarsR) & 0.2157159 & Second bid amount (Sbid) & -0.0037063 \\
\hline
\end{tabular}

Source: Survey result, 2012.

member of forest cooperative resulted in declining of WTP by -0.0481 marginal effects (Table 10).

Bids Amount (Bids): The second bid amount of the respondents is found to be negative and significant at $1 \%$ (Table 10) and this make a sense from demand and supply economic theory point of view. This is also evidenced that, as one more Yes response given for the second bid it resulted in a decrease of WTP by -0.0037063 marginal effects (Table 10).

Distance of the Household from Carbon Sequestration Forestry Project Site (DistR): There spondent's distance from forest of interest is negative and significant at 1\% to influence the respondents' WTP. The result showed that, keeping other factors constant, one more unit of increment in respondent's distance from the forest of interest will result in declining of WTP by -0.2624886 marginal effect (Table 10).

Moreover, variables like Education and Marital status of the respondents are also positive and significant at $1 \%$. Keeping other variables constant, when one of uneducated respondents promoted into formal education status the WTP increased by 0.1195714 marginal effect. The determinant factor; net family income is also positive and significant at 5\% in influencing respondents' WTP (Table 10) while increasing WTP by 0.0000322 marginal effect (Table 10).

It is possible to conclude from the result that the respective communities are willing to pay to manage carbon forestry project despite the fact that there are various pressing problems they have been facing and murmuring at lack of revenue from the sale of carbon credit. Thus, this further suggests that individuals' livelihood needs to be addressed and equitable benefit sharing from carbon credit scheme should also be given emphasis in order to ensure project sustainability. Furthermore, the conflict between community and wild animals needs thorough attention, thus planning on how to resolve the conflict between them is indispensable.

Moreover, it is quite understandable from the result that; designing appropriate sustainable development plan and establishing of forest cooperatives is not a mere solution. For the project to be sustainable, establishing of Forest Union $^{5}$ and promoting its management capacity is a crucial measure. Currently, the cooperatives are poorly equipped and understaffed especially in terms of skilled manpower in the area of financial management, Archive handling and forestry technical background. Empowering community's management capacity is so crucial not only to generate sufficient revenues from the sale of carbon credit but also to helps to ensure project sustainability.

Insignificant Explanatory Variables

Independent variables which were expected to have impact on individual's WTP for the forest of interest in the study area were included in the model. The explanatory variables like sex, age, family size and environmental knowledge of the respondents found insignificant to influence respondents' WTP for the management of forest of interest. As it was expected, sex of the respondent is positive for male but, insignificant in influencing individual's WTP. This revealed that although males are more WTP for the forest of interest than their counterparts but, their influence remains insignificant. Thus, this illustrate that both sex have better access to forest management information and decision making process. Although the respondents' environmental knowledge appeared as it was expected to positively influence individual's WTP for the forest of interest, but its impact found to be insignificant. The explanatory variables age and family size of the respondents' appeared as opposed to the expectation. The assumption for age was positive that, as the age of respondents get increased the WTP for the resource also increased. But, the survey result indicated that; as age of the respondents get increased their WTP for the forest of interest get decline. Hence, the younger community members are more interested to pay

${ }^{5}$ Forest Union is an amalgamation of forest cooperatives under one umbrella to strengthen their bargaining and management power over the resources to ensure its sustainability. 
for the management of forest than the older respondents (Table 9).

\subsection{Discussion}

The bivariate probit Model provides information about the behavior of the variables that determine peoples WTP. Thus, a significant negative relationship is found between Years of being member of forest development cooperative and WTP (p-value < 0.01). This means that the higher the years of being member of cooperatives the lesser the probability of answering yes to WTP questions. The lesson here is that, although the cooperatives benefited from the sale of carbon credit yet, no money directly channeled into individuals' pocket. This is so because, although the cooperatives have a business plan of their own the focus is only given to invest on common infrastructure like grain mills that intends to benefit the entire community being member or non member. Thus, individuals' interest should also need to be addressed in providing appropriate dividend from carbon revenue.

There is also a significant negative relationship between second bid and WTP (p-value $<0.01$ ), indicating that as the magnitude of the offered amount increases, it is less likely that individuals will be willing to pay the offered amount (Table 9). Furthermore, by keeping the influences of other factors constant, every extra second bid amount will decrease the respondents' mean willingness to pay by marginal effect of -0.0037063 . The study done at Netch-sar National Park, Ethiopia also share similar consensus that the increasing bid amount negatively and significantly influenced respondents' WTP [13].

The fact that the coefficients for first bid (Fbid) and second bid (Sbid) are negative and net income (Ntincome) is positive, i.e. the higher the income of respondents by one unit the higher the probability of answering yes to the WTP question, this validates the model in accordance with theoretical expectations. Moreover, a significant positive relationship is also found between education and WTP (p-value $<0.01)$ and marital status of the respondents and WTP (p-value $<0.01$ ), i.e. keeping other factors constant the addition of one more unit from illiteracy to formal education status in household education will positively contribute to WTP. From the result, it can also be realized that keeping the influences of other factors constant, every extra year of schooling increase the respondents' WTP by 0.1195714 marginal effect (Table 10). This implies that education could be an important policy instrument to deliver improved environmental management.

Moreover, the variable marriage also indicated that when one respondent shift from single (unmarried) status to married status it resulted in increased probability of answering yes to the WTP question. As expected, the significant negative relationship is found between distance that the respondents are living from the forest of interest and WTP (p-value $<0.01$ ), i.e. indicating that the farther the households from the forest of interest, the less willing they are to pay to manage the forest. Thus, such a community members need to be thoroughly addressed through extension work to engage them in forest management and overall decision making process. As the survey result indicated, the first question (Fbid) produced higher estimates of the mean WTP than the second question (Sbid). It is clear from the result that, the respondents become more aware of and thus make adjustment to the amount of money they have willing to pay for the second bid offered. This means that WTP estimates for the second question are preferred to the estimates for the first question. This is consistent with research on the contingent valuation debate presented by American Economic Association which argues that, the second follow-up questions helps to ensure that respondents understood the choice they were being asked to make and to discover the reasons for their answer [14]. Results of this study are also consistent with the literature of double-bounded which demonstrates that double-bound is more statistically efficient than single-bounded [7].

\section{Aggregation of Benefits}

Before conducting benefit aggregation it was advised [15] to consider four important issues in relation to sample design and its implementation. The aggregation of benefits will be valid whenever, population of interest bias, sampling frame bias, sample none response bias and sample selection bias well addressed and worked out bias free. Thus, systematic random sampling method was used in this study for selecting respondents from the members' registration list. Moreover, Protest zero responses was also included in the analysis in order to reduce the likely occurrence of bias. In addition, a face to face interview method was used to reduce data distortion. Hence, none of the above and other biases indicated in the literature part was appeared in the analysis.

If the bivariate probit model is estimated on a dichotomous choice CV question with a follow up and the parameter shows that either the mean, or variance or both differ between the initial bid-price and the follow up, hence it is the mandate of the researcher to decide on which estimates to use to calculate the WTP measure [9]. 
Hence, in order to choose the appropriate WTP among the two bivariate estimates, it needs to look into the data and the total amount for the YY and NN responses accounted for about $75 \%$ of the total responses. This means that the $2^{\text {nd }}$ bid amount was closer to the unobserved true value of the individual. For example, let the first random bid for the individual be 10 ETB and let the respondent accept the first bid. Then the $2^{\text {nd }}$ bid becomes 20 ETB, again, let the respondent accept the second bid. This means that the respondents' true WTP is greater than or equal to 20 ETB so the $2^{\text {nd }}$ bid will be a better estimate than the $1^{\text {st }}$ one. The same is true for NN answer. Even for the rest $25 \%$ of the NY and YN responses, both the first and the second bid amounts will have equal chances to be closer estimates of the true value. Hence, using the second estimate of the double bounded bivariate model to calculate as mean willingness to pay for the management of the resources in question thus, aggregate welfare benefits of the society are summarized in Table 11.

The sample mean of the WTP estimates used to derive an aggregate measure of welfare change for the entire population from which the survey sample is drawn and finally multiplied by the total population [16]. Accordingly, the data result revealed that an aggregate measure of welfare change for the entire population from which the survey sample drawn for the execution of forest management in terms of monetary value was 121,491.40 ETB per year. Finally the sample mean of the WTP estimates multiplied by the total population to get the aggregate welfare benefit and it would become 277, 256.8 ETB per year (Table 11). In further analysis, the welfare benefits would become 227,549 ETB and 104,849.3 ETB per year if we use the single bounded WTP estimate and open ended WTP estimate respectively.

\section{Cost of Forest Management}

After the withdrawal of World Vision Ethiopia, Forest Development Cooperatives are expected to take over the overall project management. Majority of project activities like seedling production and plantation was almost completed right at this time unless silvicultural operations need to be done regularly. Thus, during the last six years a total of 799,751 USD costs have been incurred to successfully accomplish the aforementioned project activities. After taking over the project from World Vision Ethiopia, the cooperatives will be expected to incur a cost of 5.5\% from carbon revenue as carbon reversals ${ }^{6}$ and operation costs ${ }^{7}$. Therefore, from 2014-2017 on average the overall estimated cost for execution of carbon reversals and field operation is amounting to 180,532 ETB (10,000 USD) per year. If the anticipated forest damage will not occur, the cooperatives do not liable to incur carbon reversal costs.

\section{Comparison of WTP and Cost of Forest Management}

As per the survey result, in aggregate the community (three Kebeles) willing to pay 121,503 ETB per year to maintain forest management. If the same mean WTP is extrapolated over the whole cooperative members (4975 members) the community WTP 277,256.80 ETB per year to manage the forest of interest. Thus, the net benefit which the community will be expected to use as a welfare improvement is accounted to 96,724.80 ETB per year. Moreover, the community also has an opportunity to get additional revenue from the sale of carbon credit which accounted to 726,000 USD until 2017 (Table 12). From this amount on average a total of 80,666.67 USD $(1,456,291.53 \mathrm{ETB})^{8}$ will annually be received by the community. In summary, the community will have a net welfare benefit of 1,553,016 ETB from both their own contribution expressed through WTP and revenue from the sale of carbon credit per annum. Moreover, the respondent also expressed their interest on average to contribute $26 \%$ (20,973 USD out of $80,666.67$ USD) of the revenue from the sale of carbon credit per year for reinvestment

Table 11. Average and aggregate benefit measures by forest cooperatives.

\begin{tabular}{cccc}
\hline Kebeles & Population size & Mean WTP (ETB) & Total WTP (ETB) \\
\hline Abela Longena & 851 & 55.73 & $47,426.23$ \\
Hobicha Bada & 840 & 55.73 & $46,813.65$ \\
Abela Shoya & 489 & 55.73 & $27,251.97$ \\
Sample total & 2180 & 55.73 & $\mathbf{1 2 1 , 4 9 1 . 4 0}$ \\
Population total & 4975 & 55.73 & $\mathbf{2 7 7 , 2 5 6 . 8}$ \\
\hline
\end{tabular}

Source: Survey result, 2012.

\footnotetext{
${ }^{6}$ Costs incurred for replacing damaged forest (fire hazard, tree disease and forest encroachment) by replanting trees and costs for carbon monitoring and quality assurance (source: World vision Ethiopia, Environment and climate change department head).

${ }^{7}$ Costs incurred for field staff and office supplies.

${ }^{8}$ Currency Exchange rate of National Bank of Ethiopia as of 24/06/2012; 1 USD exchanged rate for 18.0532 Ethiopian birr (ETB).
} 
while they are eager to share the remaining $74 \%$ on individual basis. In contrast, cooperatives leaders neglect individuals' interest and generally preferred to reinvest on construction of common infrastructures like grain mill and grain store which will benefited the entire community regardless of being member or non member of forest development cooperatives.

To conclude with, total project implementation and Carbon compliance Costs that will be incurred by cooperatives from 2014 until 2017 amounting to a total of 40,000 USD ${ }^{9}$, which annually on average for the coming four years is about 10,000 USD (180,532 ETB). Thus, in comparing the cost of forest management, it was found that the society will be able to save net $96,724.80$ ETB as a welfare improvement each year from own contribution as expressed in their WTP. But, if the 26\% (378,629.80 ETB) contribution from carbon revenue will be disbursed to welfare improvement, the society could be able to save a net benefit of 475,354.60 ETB per year. Thus, this amount will help them to run the project under sustainable basis in the absence of World Vision.

The Forest Development Cooperatives signed sub-Emission Reduction Purchase Agreement (ERPA) with The World Bank to deliver the amount agreed on ${ }^{10}$ through project life, 30 Years. Thus, the annual revenue from the sale of carbon credit computed by multiplying the annual amount of contracted Emission Reduction (ER) by 4.4 USD under constant market price (Table 12).

\section{The Prospect of Community in Forest Management: Respondents' General Comment}

At the end of the interview key respondents were encouraged to freely comment on the overall aspect of forest management and the anticipated situation after World Vision Ethiopia hand over the project to community. This investigation is so important to see the level of their awareness about the project, sense of ownership, the concern they have, to indicate the way forward and to investigate their general recommendation to World Vision, government and the entire community.

As per the survey result $66.66 \%$ of the key respondents revealed that they are well capable, better equipped and have good sense of ownership. The remaining 33.33\% of respondents replied that, following the withdrawal of World Vision Ethiopia; there is a likely that the forest will be exposed to exploitation due to various reasons. They indicated that, corruption (power abuse, lack of transparency and money confiscations by cooperative leaders) and conflict between wild animals and human (33.33\%) are the most pressing challenges. The other dimension of challenge is lack of interest to protect forest as World vision did. The other concern was insufficient technical and legal support from respective government and lack of awareness among non-members (Table 13 and Table 14).

Table 12. Cumulative amount of Emission Reduction (ER) to be transferred to the buyer.

\begin{tabular}{ccccc}
\hline Reporting Year & Period & $\begin{array}{c}\text { Annual amount of contract } \\
\text { ER to be transferred }\end{array}$ & $\begin{array}{c}\text { Total amount of } \\
\text { revenue (USD) }\end{array}$ & $\begin{array}{c}\text { Cumulative amount of contract ER to be } \\
\text { transferred }\left(\mathrm{Co}_{2} \text { ton equivalent }\right)\end{array}$ \\
\hline $1^{\text {st }}$ & 2009 & 7769 & $34,183.6$ & 7769 \\
$2^{\text {nd }}$ & 2010 & 11,117 & $48,914.8$ & 33,886 \\
$3^{\text {rd }}$ & 2011 & 14,900 & 65560 & 51,184 \\
$4^{\text {th }}$ & 2012 & 17,398 & 76551.2 & 70,549 \\
$5^{\text {th }}$ & 2013 & 19,365 & 85206 & 91,598 \\
$6^{\text {th }}$ & 2014 & 21,049 & 92615.6 & 114,225 \\
$7^{\text {th }}$ & 2015 & 22,627 & 99558.8 & 138,429 \\
$8^{\text {th }}$ & 2016 & 24,204 & 106497.6 & $165,00016^{11}$ \\
$9^{\text {th }}$ & 2017 & 26,571 & 116912.4 & \\
Grand total & & $\mathbf{1 6 5 , 0 0 0}$ & $\mathbf{7 2 6 , 0 0 0}$ &
\end{tabular}

Source: World Vision Ethiopia, 2012.

${ }^{9}$ This include costs like carbon reversals and field staff operational costs.

${ }^{10}$ The project can produce a total of $880,295 \mathrm{t} \mathrm{co}_{2}$ equivalent through project entire life i.e. 30 years (starting from 2009).

${ }^{11}$ The first round total amount of CER (Certified Emission Reduction) Contract signed between the community and the purchaser, World Bank through 2009 to 2017 with market value of 4.4 USD per ton of carbon dioxide. While the remaining CER determined by future market price. Source: World vision Ethiopia, direct discussion with environment and climate change department Manager as of 20/08/2012 at Addis Ababa. 
Table 13. Descriptive statistics of key respondents view on the sense of ownership and anticipated challenges.

\begin{tabular}{lll}
\hline Respondent's view & Frequency & $\%$ \\
\hline Well established sense of ownership and thus, there is anticipated challenges & 8 & 66.66 \\
$\begin{array}{l}\text { Although there is improved sense of ownership but there will be an anticipated } \\
\text { challenges which negatively impacted the forest of interest }\end{array}$ & 4 & 33.33 \\
Total & 12 & 100 \\
\hline
\end{tabular}

Source: Survey result, 2012.

Table 14. Descriptive statistics of anticipated challenges.

\begin{tabular}{lll}
\hline Sources of anticipated challenges & Frequency & $\%$ \\
\hline Corruption (lack transparency by coops leaders) & 2 & 16.68 \\
Damage by Wild animals to human being and their produce & 4 & 33.33 \\
Fire damage by illegal wild honey extractors and protection against wild animals & 1 & 8.33 \\
Lack of commitment to protect forest from encroachment & 3 & 25 \\
Lack of technical and legal support from government & 1 & 8.33 \\
Lack of awareness by non cooperative members & 1 & 8.33 \\
Total & 12 & 100 \\
\hline
\end{tabular}

Source: Survey result, 2012.

Finally, the respondents provided important and valid comments (Table 15) on how to overcome and become successful in their endeavors. As long as there is a resource, there is likely for conflict to happen in order to satisfy their daily need. Thus, what matters is not a conflict, but how the conflicting issues settled and resolved. Communities are not all the same and likeminded, as a result some gaps may happen to hinder activities. Thus, by considering all these situations as something normal, the respondents provide important recommendations. These include; government bodies should take full responsibility through provision of necessary technical and legal support; World Vision Ethiopia, should also committed in providing proper supervision, in such a way that avoid corruption through creating transparency in financial audit report and faire income distribution among cooperatives members in stretching from a remote distance. Moreover, the conflict between wild animals and human can be reduced by conducting frequent and thorough thinning operation on thick forest so that the number will easily be checked through natural food chain balance system. If in case the situation become serious, in consultation with concerned government offices it is better to reduce the number of wild animals in the way to create revenue to community by attracting tourism through legal hunting game sporting.

\section{Conclusions}

In this study, CVM was used to elicit households' willingness to pay for managing carbon sequestration forestry project in Humbo Community Assisted Natural Regeneration Forestry project of Woliata Zone, Humbo Woreda.

Respondents were asked about their WTP per year to manage project for the coming ten years. Thus, the respondents expressed their WTP average payment of 104.38 ETB and 55.73 ETB per year for first and second bids respectively. This model could be found more accurate in evaluating the respondents' true preferences or unobserved behavior [7].

The estimation of bivariate probit model using covariates indicated that the year of being membership of cooperatives and the offered second bid amount were the variables which negatively and significantly influenced WTP at $1 \%$ significance level. This result showed that those individuals who had been a member for longer time reacted negatively due to limited access to benefit sharing from the sale of carbon revenue. Furthermore, the negative sign of bid amount makes a sense in that the interest of individuals paying for the resources getting decline as bids amount increased; because income constraint influences individuals' preferences which comply with demand and supply theory. Distance from forest of interest is the explanatory variable, which negatively and significantly influences their WTP at $1 \%$ significance level. Thus, those cooperative members who are living at a distant place from project needs more training and forestry related extension work. As it was expected, the increment 
Table 15. Descriptive statistics of comments provided by respondents.

\begin{tabular}{lll}
\hline Major comments & Frequency & $\%$ \\
\hline $\begin{array}{l}\text { Technical and legal support from government side } \\
\text { Close supervision by World Vision Ethiopia to create transparency and avoid corruption }\end{array}$ & 65 & 30 \\
$\begin{array}{l}\text { Cooperatives should work on how to attract non members into development activities, } \\
\text { and mobilizing cooperative members in forest management activities }\end{array}$ & 55 & 43 \\
Total & 218 & 27 \\
\hline
\end{tabular}

Source: survey result, 2012.

in households' income will positively and significantly influence their WTP and this makes a sense from economic theory point of view. Thus, creating diversified income sources will more encourage community to pay for the management of the project.

The aggregate measure of welfare change for the sample population was 121,491.40 ETB while for the entire population is $277,256.8$ ETB per year respectively. The aggregate net welfare estimation remaining after covering both carbon reversal and operation costs amounted to 96,724.80 ETB per year. If the 26\% of carbon revenue will be contributed by the community as they expressed in their WTP, the total welfare benefit will add up to 475,354.60 ETB.

Among the various environmental problems encountered by the community, before the onset of the project, deforestation was identified as the most pressing problem followed by soil erosion and climate variability in the study site. However, after project intervention, the community is able to benefit from improved environmental co-benefits and create job opportunities. Thus, frequent and cautious technical and legal support both from government and World Vision is indispensible to ensure sustainable resource management. Moreover, improved environmental condition will also contribute to county's poverty reduction strategy. Environmental co-benefits should gear towards improving the livelihood of respective community. In this respect, the government should give emphasis to both cooperatives capacity building and environmental rehabilitation efforts to ensure sustainable resources management.

Furthermore, the study result revealed that although the community got environmental co-benefits, there was a conflict between respective community and wild animals. Thus, to overcome the challenge, the community will be enforced to set fire on forest to chase them out of the forest. Moreover, some of the respondents also expressed their concern that the forest will be susceptible to encroachment during prolonged drought reason thus; they might be forced to make charcoal and collect firewood for sale as a copping strategy. Therefore, in order to avert the situation, government should closely work with community on how to overcome the challenge through providing trainings and also look for legal hunting as a means of income sources for the community. Moreover, during crop failure, the government should also provide immediate response or aid support to calm the situation.

\section{Recommendation}

Based on the findings of this study, the policy recommendations could be generalized into the following points.

- Due to the remarkable effort of the community, the once severely degraded mountain has fully rehabilitated and able to provide ecological and economical benefits to the community. Thus, such a good lessen should be scaled up and scaled out both by governmental and nongovernmental organizations into similar environment.

- During the designing of forestry project, conducting of thorough assessment and critical planning in due consideration of the conflict between human being and wild animals. Thus, the government should make some kind of measures/policy decision on how to manage the risk of wild animals to the respective community.

- The application of economic valuation techniques found to be important to measure how the people value the environment/ecosystem values expressing their willingness to ensure sustainable forest management. Thus, higher institutions and individual researchers should conduct the economic valuation in similar areas to inform policy makers.

- It is better for the government and World Vision Ethiopia to discuss and reach on consensus with community in the modality of benefit sharing from the sale of carbon credit instead of fully reinvesting in common so- 
cial infrastructure facilities. It is because of lack of common understanding that, those individuals who spent more time in cooperative was hesitated (negatively and significantly react) to pay for the resource management. It is quite clear that, most of infrastructures development is the responsibility of the government. Thus individuals should benefit from the sale of carbon credit to improve their livelihood as well as to ensure sense of ownership.

- Creating diversified sources of income will improve the livelihood of local community and consequently increase their contribution (WTP) to manage the forest of interest. Thus, in addition to investing on common infrastructure, cooperatives should work more on creating diversified sources of income at individual level to improved access to credit.

\section{Acknowledgements}

First and foremost, I would like to praise the Almighty GOD for His leading Hands that made me courageous enough to successfully finalize this study. I am extremely grateful for the ongoing support, frequent advice and valuable comments of Dr. Zeleke Ewnetu and Dr. Yemiru Tesfaye Lecturers at Wondo Genet College of Forestry and Natural Resources.

I extend my gratitude to World Vision Ethiopia for financial support and permission for course work. I am also thankful to World Vision Ethiopia staff members, Hailu Tefera, Eshetu Hailu and Daniel Nesibu for their logistical support and tireless advice.

I am indebted to my beloved spouse Emebet Teshome for her day-to-day encouragement, support in data entry and analyses and for her endurance to bear the entire family burden during my engagement in course work. Special thanks also go to my lovely Children, Bontu Shanko, Bethel Elmi, Nemeab Elmi and Dawit Elmi for their endurance during my engagement in course work.

Finally, I am also thankful to all unstated colleagues and Humbo forest development cooperatives administration for their assistance in all circumstances in data collection and providing the related information.

\section{References}

[1] FAO (2011) State of the World's Forests. Food and Agriculture Organization of the United Nations, Rome.

[2] Bekele, M. (2001) Forestry Outlook Studies in Africa (FOSA) Ethiopia.

[3] WVE (2011) World Vision Ethiopia Sodo Community Managed Forestry and Agro-Forestry Project: Community Climate Biodiversity Alliance (CCBA). Unpublished.

[4] WVE (2012) Humbo Assisted Natural Regeneration Forestry Project (Project Terminal Report). Unpublished.

[5] Gurmu, D. (2006) Humbo and Soddo Community-Managed Natural Regeneration Project. Working Paper on Forestry, Ethiopia. Unpublished.

[6] WVE (2006) Humbo Assisted Natural Regeneration Forestry Project; Project Design Document (PDD). Unpublished.

[7] Cameron, T.A. and Quiggin, J. (1994) Estimation Using Contingent Valuation Data from a "Dichotomous Choice with Follow-Up” Questionnaire. Journal of Environmental Economics and Management, 27, 218-234. http://dx.doi.org/10.1006/jeem.1994.1035

[8] Werner, M. (1999) Allowing for Zeros in Dichotomous-Choice Contingent-Valuation Models. American Statistical Association Journal of Business \& Economic Statistics, 17, No. 4

[9] Haab, T.C and McConnell, K.E. (2002) Valuing Environmental and Natural Resources: The Econometrics of NonMarket Valuation. Edward Elgar Publishing, Northampton. http://dx.doi.org/10.4337/9781843765431

[10] MOFED (2010) Growth and Transformation Plan (GTP) 2010/11-2014/15. The Federal Democratic Republic of Ethiopia, Addis Ababa.

[11] Gujarati, D.N. (2004) Basic Econometrics. 4th Edition, McGraw-Hill Companies.

[12] Ready, R.C. and Hu, D. (1995) Statistical Approaches to the Fat Tail Problem for Dichotomous Choice.

[13] Belete, Z. and Assefa, Y. (2004) Willingness-to-Pay for Protecting Endangered Environments: The Case of Nechsar National Park, Ethiopia.

[14] Portney, P.R. (1994) The Contingent Valuation Debate: Why Economists Should Care? Journal of Economic Perspective, 8, 3-17. http://dx.doi.org/10.1257/jep.8.4.3

[15] Mitchell, R.C. and Carson, R.T. (1989) Using Surveys to Value Public Goods: The Contingent Valuation Method. Resources for the Future, Washington DC. 
[16] Hanemann, M., Loomis, J. and Kanninen, B. (2007) Statistical Efficiency of Double-Bounded Dichotomous Choice Contingent Valuation. American Journal of Agricultural Economics, 73, 1255-1263.

http://dx.doi.org/10.2307/1242453 